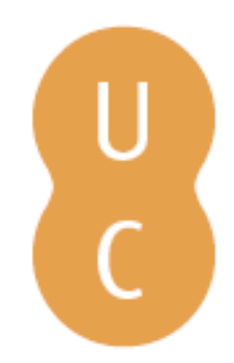

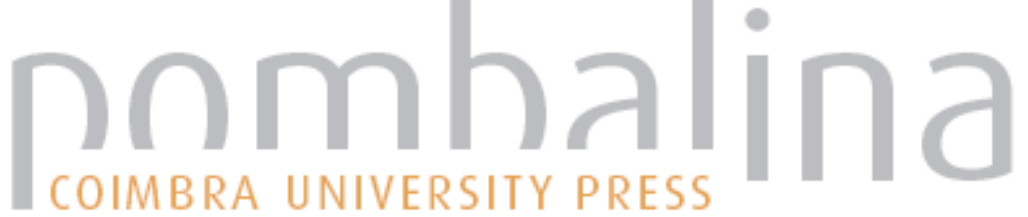

Historia de la alimentación: relaciones entre España y Portugal en la edad moderna, a través de los recetarios

Autor(es): Pérez Samper, María Ángeles

Publicado por: Imprensa da Universidade de Coimbra; Annablume

URL

persistente: URI:http://hdl.handle.net/10316.2/39661

DOI: $\quad$ DOI:https://doi.org/10.14195/978-989-26-1191-4_32

Accessed : $\quad$ 26-Apr-2023 12:15:22

A navegação consulta e descarregamento dos títulos inseridos nas Bibliotecas Digitais UC Digitalis, UC Pombalina e UC Impactum, pressupõem a aceitação plena e sem reservas dos Termos e Condições de Uso destas Bibliotecas Digitais, disponíveis em https://digitalis.uc.pt/pt-pt/termos.

Conforme exposto nos referidos Termos e Condições de Uso, o descarregamento de títulos de acesso restrito requer uma licença válida de autorização devendo o utilizador aceder ao(s) documento(s) a partir de um endereço de IP da instituição detentora da supramencionada licença.

Ao utilizador é apenas permitido o descarregamento para uso pessoal, pelo que o emprego do(s) título(s) descarregado(s) para outro fim, designadamente comercial, carece de autorização do respetivo autor ou editor da obra.

Na medida em que todas as obras da UC Digitalis se encontram protegidas pelo Código do Direito de Autor e Direitos Conexos e demais legislação aplicável, toda a cópia, parcial ou total, deste documento, nos casos em que é legalmente admitida, deverá conter ou fazer-se acompanhar por este aviso.

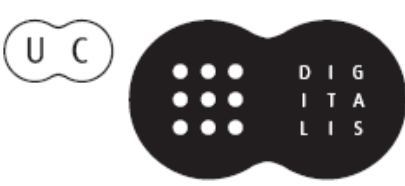




\title{
Historia de la alimentación: Relaciones entre España y Portugal en la EDAD MODERNA, A TRAVÉS DE LOS RECETARIOS ${ }^{1}$ History of food: Relations between Spain and Portugal in the early modern age
}

\author{
María Ángeles Pérez Samper \\ Universidad de Barcelona \\ Facultad de Geografía e Historia \\ HAR2014-52850-C3-3-P. \\ GEHMO (2014 SGR 173) \\ angelesperez@ub.edu
}

\begin{abstract}
Resumen: Una comparación cuidadosa de las mutuas influencias entre la cocina española y portuguesa en la edad moderna muestra la existencia de muchas pruebas que permiten concluir la existencia de una cocina común ibérica, con una fuerte identidad diferencial frente a otras cocinas europeas, aunque con diversas características regionales, igualmente bien definidas, como señalan las coincidencias y diferencias entre la cocina portuguesa y la cocina española, entre la cocina atlántica y la cocina mediterránea.

Palabras clave: alimentación, España, Portugal, edad moderna, cocina ibérica, cocina cortesana, recetarios de cocina.
\end{abstract}

Aвstract: A careful comparison of the mutual influences between the Spanish and Portuguese cuisine in the early modern age shows that there is much evidence to support the conclusion that there is a common Iberian cuisine, with a strong identity differential against other European cuisines, although with different regional characteristics equally well defined, as pointed out by the similarities and differences between the Portuguese and Spanish cuisine, between the Atlantic and the Mediterranean cuisine.

Keywords: food, Spain, Portugal, Early Modern Age, Iberian cuisine, courtly cuisine, cookbooks.

${ }^{1}$ Este trabajo se ha realizado en el marco del Proyecto CICYT. Convocatoria 2011. Ministerio de Ciencia e Innovación. Referencia: HAR2014-52850-C3-3-P. Título del proyecto: "Maneras de vivir en la España Moderna: Cataluña y Barcelona". Y en el marco del "Grup de recerca consolidat" (AQU.Generalitat de Catalunya), Referencia 2014 SGR 173.GEHMO Grup d'Estudis d'Història del Mediterrani Occidental. Societat, poder i cultura a l'època moderna (Universidad de Barcelona). 


\section{España y Portugal, coincidencias de espacio y tiempo}

Situada entre el Mediterráneo y el Atlántico, a la península ibérica se le puede aplicar la frase de Pierre Chaunu: "el más mediterráneo de los países atlánticos, el más atlántico de los países mediterráneos". ${ }^{2}$ Comparten España y Portugal el mismo espacio geográfico, por lo que los productos básicos de su alimentación tradicional son prácticamente los mismos, comenzando por la tríada mediterránea del pan, el vino, y el aceite. Esa base común les dio las condiciones para crear una cultura culinaria compartida, con perfiles bien definidos, que le daban una personalidad propia, siempre con peculiaridades diferenciales, pero con muchos puntos comunes. Evidente su unidad sobre todo en comparación con otros países europeos, con los que existían proximidades, pero también marcados distanciamientos. ${ }^{3}$

En la edad moderna al Mediterráneo se sumó primero el Atlántico y después el Pacífico. Portugal y España fueron los dos países que encabezaron la expansión planetaria, participando en un magno intercambio mundial de alimentos entre los diversos continentes, e incorporando así a su alimentación productos venidos de oriente, como las especias, y de occidente, como el maíz, la patata, el tomate, el pimiento y el cacao. Intercambiaron no solo los productos, sino también su tecnología y su cultura. $\mathrm{Y}$ así nacieron nuevas cocinas de síntesis en los más diversos países de los continentes entonces conocidos.

La misma situación en el espacio y experiencias históricas compartidas a lo largo del tiempo llevaron a la creación de una cultura culinaria común, con múltiples coincidencias y recíprocas influencias, aunque manteniendo perfiles peculiares, en función de características regionales y de niveles económicos y sociales. Este trabajo pretende analizar algunos ejemplos, encaminados a poner de relieve la existencia de una alimentación y una cocina ibéricas.

\section{LA MESA de la Emperatriz IsAbel}

Una de las relaciones alimentarias más estrechas entre los dos países pasó a través de la cocina cortesana. Las dos monarquías construyeron a lo largo del tiempo múltiples lazos entre las dos familias reales, por lo que la alta cocina cortesana compartió un mismo estilo y cruzó numerosas influencias, tanto en la preparación de los alimentos como en la manera de servirlos. De alguna manera podría decirse que, aunque con algunas particularidades, existió un modelo de alimentación ibérica, en la que ambos países estuvieron integrados.

\footnotetext{
${ }^{2}$ Chaunu 1955.

${ }^{3}$ Bruegel, M. y Laurioux, B. (eds.) 2002.
} 
Las bodas reales sirvieron de vínculo dinástico y político, pero también culinario. El matrimonio real debía ser un matrimonio entre iguales, por lo que el rey sólo podía casarse con una mujer perteneciente a la realeza, y como resultado las reinas fueron de origen extranjero durante la edad moderna. Preferentemente la Monarquía Española estableció enlaces con la dinastía Avís del vecino Portugal, también con los Valois o los Borbones de la igualmente vecina Francia, y con la rama vienesa de la dinastía Habsburgo. Procedentes de otros reinos, otras culturas y otros sistemas alimentarios, las Reinas por sus gustos particulares, por los cocineros que formaban parte de su séquito, por sus costumbres en la mesa, sirvieron entre otras muchas cosas, como enlaces entre su país de origen y su país de destino de las culturas de la cocina y de la mesa

Como una de las cuestiones más fundamentales de un estilo de vida es la forma de comer, se consideraba que la reina en su vida privada no debía ser obligada a cambiar sus gustos y costumbres, cosa siempre difícil, y se aceptaba que continuara conservando parte de sus hábitos y preferencias de alimentación. Las reinas traían consigo cocineros de su país de origen, que con frecuencia se quedaban en la corte española.

La organización de la Casa de la reina era fundamental para todo lo relacionado con la alimentación. Cuando Juana I, hija de los Reyes Católicos, contrajo matrimonio con Felipe I de Habsburgo, como heredera del reino de Castilla mantuvo la reglamentación castellana en su Casa. Igualmente, su hija María de Trastámara, casada con Manuel I de Portugal, mantuvo y conservó los usos castellanos. La emperatriz Isabel, esposa de Carlos V, heredó gran parte del servicio y de las normas castellanizadas de la Casa de su madre, favoreciendo así la continuación, junto con otras propias de la portuguesa, cuya influencia se manifestó especialmente en el servicio a la mesa, creando un modelo a imitar para las Casas de las reinas e infantas posteriores.

En tiempos de los primeros Habsburgo la tradición castellana y la portuguesa se combinaría con la tradición borgoñona. Con el advenimiento de la casa de Austria se produjeron cambios importantes, por la creciente complejidad de la organización de la corte y del ceremonial. En tiempos de Carlos V, su origen flamenco y su condición de Emperador se reflejó en la corte española, con la introducción de la etiqueta borgoñona y de nuevos gustos culinarios. Su boda con una infanta portuguesa, Isabel, obligó también a introducir novedades. La Casa de la Emperatriz se organizó a la portuguesa, de acuerdo con las costumbres de su país de origen.

Pero la mesa de Isabel debía ser mucho más que la mesa de una infanta portuguesa o de una reina española, debía tener la solemnidad de la mesa de una emperatriz. Aunque algunos cortesanos españoles ponían como ejemplo la corte más austera de Isabel la Católica y proponían una simplificación 
de la Casa de la Reina, en cambio, al mismo tiempo echaban en falta un mayor ceremonial en el servicio de la mesa. Para esta función, además de las damas, se juzgaban necesarios tres o cuatro maestresalas que ayudasen por turnos a servir a la Emperatriz en la mesa. Junto a la figura del maestresala se proponían también diversos trinchantes y pajes.

Finalmente en la mesa de la emperatriz Isabel se respetó en lo esencial la tradición de comer al estilo de Portugal. Una carta del obispo fray Antonio de Guevara al Marqués de Los Vélez, de 1532, proporciona interesante información sobre la mesa de la Emperatriz. ${ }^{4}$ Guevara, prelado y cortesano, conocía bien la vida de la corte y especialmente el ritual de la comida de Doña Isabel, pues asistía regularmente para cumplir la función de bendecir la mesa: "Decís, señor, que os escriba si me hallo alguna vez al comer de la Emperatriz, y qué son las cosas y viandas que más come agora que es invierno. Como agora hay pocos prelados en la Corte, yo, señor, me hallo cada día en su comer, y a su cenar; no para ver, sino para la mesa le bendecir..."

La Emperatriz comía de manera muy solemne y ceremonial, pero muy triste, pues como decía Guevara en su carta, comía en un lugar frío, comía platos que ya no estaban calientes, comía sola y comía en silencio:

"A lo que decís qué come y cómo come la Emperatriz, sé os, señor, decir que come lo que come, frío y al frío, sola y callando, y que la están todos mirando. Si yo no me engaño, cinco condiciones son estas que abastaba una sola para darme a mí muy mala comida. Agora, señor, es invierno, en el cual, naturalmente, es tiempo triste, frío y encogido, y cada uno huelga de comer al fuego su comida, y caliente, y acompañado, y hablando, y que no le esté nadie mirando, porque en tiempo de regocijo, cuando alguno no come ni sirve, sino que está callando, y entre sí pensando, osaría yo decir del tal que no nos mira, sino que nos acecha."

Mucha ceremonia, pero, en opinión de Guevara, torpeza y mezquindad, muchas veces derivadas de las exigencias del mismo ritual:

"Comer en el invierno algún manjar frío también es gran desabrimiento, porque las cosas resfriadas dañan al estómago y no tienen apetito. Comer el hombre solo también es gran soledad, que al fin no se deleita el hombre generoso tanto con el manjar que come, cuanto se huelga con la compañía que a la mesa tiene. Comer uno sin hablar y sin se escalentar, diría yo que procede lo uno de torpedad y lo otro de mezquindad."

\footnotetext{
${ }^{4}$ Guevara $1850: 1^{\text {a }}$ p. t. $13,97$.
} 
En definitiva, la comida de la Emperatriz se desarrollaba en unas condiciones muy poco envidiables. Los deberes de los soberanos se imponían a las reglas de la buena mesa: "No son los príncipes obligados a estar subjectos a estas reglas porque les es forçoso tener gran severidad en el vivir y tener gran auctoridad en el comer. Sea, señor, como fuere y coma como mandare, que al fin yo tengo a Su Magestad más envidia a la paciencia que tiene que no a la comida que come."

Comía la Emperatriz y comía la mujer. A la mesa se servía no solo la comida de una persona concreta, sino la de un símbolo, la Corona. A la institución había que servirla de acuerdo con su grandeza, por lo que el servicio estaba compuesto de muchos y ricos platos; en cambio, a la persona con mucho menos le bastaba, sobre todo si se trataba de una mujer austera y moderada, muy diferente de su esposo, que hacía gala de un apetito incontrolable: "Los manjares que le sirven a la mesa son muchos, y de los que ella come son muy pocos, porque si no me engaña su philosomía, es la Emperatriz de muy buena condición y de flaca complisión."

Lo que comía Doña Isabel era relativamente sencillo: "De lo más que come es melones de invierno, vaca salpresa, sopas abajadas, palominos duendos, menudos de puerco, ansarones gruesos y capones asados; de manera que come con lo que los otros se empalagan y aborresce por lo que los rústicos sospiran." Por el contrario, de lo mucho que se le ofrecía, dejaba una gran parte:

"Pónenle delante pavones, perdices, capones, fracolines, faisanes, manjar blanco, mirrauste, pasteles, tortradas y otros varios géneros de golosinas, de lo cual todo no solo no quiere comer, más aún muestra pesadumbre en lo mirar; por manera que el contentamiento no consiste en lo mucho o poco que tenemos, sino en solo aquello a que nos inclinamos."

De igual moderación era Doña Isabel en el beber, bebía poco y el vino que bebía lo rebajaba con mucha agua: "En toda la comida no bebe más de una vez, y esta es, no de vino puro, sino de agua envinada; de manera que con sus escamochos ninguno podrá satisfacer el apetito, ni menos matar la sed."

En una corte tan espléndida en banquetes, la Emperatriz Isabel rompía la costumbre de comer muchísimo y comer de manera sofisticada. Doña Isabel, a diferencia de Don Carlos, sí parecía seguir las recomendaciones del médico del Emperador, Luis Lobera de Ávila, que por aquellos años, en 1530, escribió una obra titulada Vanquete de nobles caballeros, en que recomendaba moderación en el comer y en el beber:

"Porque los caballeros y señores de España y de Francia y de Alemaña como de Italia y otras partes usan agora y tienen mucho en costumbre de hazerse los unos a los otros banquetes y beber autant que agora dizen. Dire las cosas que el buen 
vanquete ha de llevar e los daños que de usarlos mucho se siguen y particularmente de cada cosa que en los tales banquetes entran y el daño y provecho que hazen y sus complessiones."

La mesa de la emperatriz Isabel se servía "al estilo de Portugal”, manteniendo la Emperatriz las costumbres de su corte de origen. Según explicaba Guevara:

"Sírvese al estilo de Portugal; es a saber, que están apegadas a la mesa tres damas y puestas de rodillas, la una que corta y las dos que sirven, de manera que el manjar traen hombres y le sirven damas. Todas las otras damas están allí presentes en pie y arrimadas, no callando sino parlando, no solas sino acompañadas; así que las tres dellas dan a la Emperatriz de comer y las otras dan bien a los galanes que decir."

A diferencia del estilo castellano de tiempos de los Reyes Católicos, que era sencillo, pero grave, y del borgoñón, extremadamente solemne y complicado, el estilo portugués estaba lleno de autoridad, pero también de regocijo. Como decía Guevara en su carta: "Auctorizado y regocijado es el estilo portugués; aunque es verdad que algunas veces se ríen tan alto las damas y hablan tan recio los galanes, que pierden su gravedad y aún se importuna Su Magestad". Mientras la emperatriz Isabel mantenía siempre el estilo de autoridad y seriedad que le correspondía por su rango, las damas y caballeros que asistían al acto de la comida parece que perdían la compostura, hablando y riendo con gran regocijo.

El modelo de servicio de la mesa de la reina, establecido en tiempos de la Emperatriz estaba destinado a permanecer. La información proporcionada por Fray Antonio de Guevara sobre el ritual de servicio de la mesa de Doña Isabel pasó, palabra por palabra, a las etiquetas palaciegas. En las ordenanzas mandadas establecer por Felipe II, para la mesa de la reina se decía:

"Sírvese al estilo de Portugal; es a saber, que están apegadas a la mesa tres damas y puestas de rodillas, la una que corta y las dos que sirven, de manera que el manjar traen hombres y le sirven damas. Todas las otras damas están allí presentes en pie y arrimadas, no callando sino parlando, no solas sino acompañadas; así que las tres dellas dan a la Emperatriz de comer y las otras dan bien a los galanes que decir. Autorizado y regocijado es el estilo portugués; aunque es verdad que algunas veces se ríen tan alto las damas y hablan tan recio los galanes, que pierden su gravedad y aún se importuna Su Magestad". ${ }^{6}$

\footnotetext{
${ }^{5}$ López Piñero 1991.

${ }^{6}$ Hordenanzas y etiquetas que el rey nuestro señor don Pelipe segundo rey de las Españas mando que guardasen por los criados y criadas de la real cassa de la reyna nuestra señora, dadas en treinta y uno
} 
No solo se introdujeron cambios ceremoniales, sino también cambios gastronómicos. La organización de la Corte en la Monarquía Española era compleja, respondía a las personas reales, pero respondía también a los diversos reinos y estados que configuraban el conjunto de la Monarquía. La introducción de la casa de Borgoña en tiempos de Carlos V, se sumó a las Casas ya existentes de Castilla y Aragón. A partir de la boda de Carlos V con la emperatriz Isabel la corte se desdobló y pasó a estar formada por la Casa del Rey y la Casa de la Reina. Las cocinas también se desdoblaron. La duplicación de las Casas tenía que ver con el concepto de la Monarquía y con la organización del servicio. La duplicación también respondía a la voluntad de respetar algunos aspectos del estilo de vida de las reinas.

Si el emperador Carlos, acostumbrado a la alimentación flamenca y germánica, se adaptó a la alimentación española, manteniendo muchos de sus gustos de procedencia, algo similar le sucedería a la emperatriz Isabel, respecto de su origen portugués y su nuevo reino español, así como de las influencias borgoñonas. ${ }^{7}$

\section{RECETARIOS MANUSCRITOS DE GRANDES DAMAS}

Desde el siglo XV y durante todo el XVI la relación entre la corte española y la portuguesa fue muy estrecha y continuada y existen numerosos testimonios en el ámbito alimenticio, uno de los más significativos son los recetarios manuscritos de grandes damas hispano-portuguesas. ${ }^{8}$

Muy interesante es un manuscrito, el Livro de receptas de pivetes, pastilhas elvvas perfumadas y conservas. ${ }^{9}$ Se trata de un manuscrito escrito con diversos tipos de letra, de los siglos XVI y XVII, en que se recopilan, en etapas sucesivas, una serie de recetas de alimentación, cosmética, perfumería y medicina, en total 108. El manuscrito consta de 65 folios. Aunque no se refiere expresamente a la mesa regia, el recetario refleja muy bien la relación existente entre las dos cortes, la española y la portuguesa, en materia de alimentación. Al principio está escrito en portugués, en letra más antigua, de finales del XV o principios del XVI, después continúa en castellano.

Como expresión de la importancia que las mujeres siempre han tenido en la transmisión y difusión de saberes culinarios, existen referencias a diversas damas. En el folio 1 figura la siguiente anotación: "Este lyvro he de Joana Fernandez". En una de las recetas hace referencia a la "Emperatriz", es decir

de diziembre de mil quinientos y setenta y cinco años. y refrendadas por su secretario de estado Martín de Gaztelu. AGP, Sección Histórica, caja 49, exp. 3.

${ }^{7}$ Pérez Samper 2000: V, 497-540.

${ }^{8}$ Pérez Samper 1997: 121-154.

${ }^{9}$ B.N.E, Mss. 1462. 
la infanta portuguesa Doña Isabel (1503-1539), casada en 1526 con el emperador Carlos V. También se menciona a la "Reina”, que podría ser la reina de Portugal, que en esta época era una infanta española, Doña Catalina, hija de Doña Juana y Don Felipe, casada con Juan III, que fue reina de Portugal de 1525 a 1557 y regente hasta 1562 .

En el recetario abundan las recetas de dulces, como la de carne de membrillo, que era extraordinariamente popular entre todas las clases sociales.

\section{"Carne de benbrillo colorada}

A seis libras de carne, ocho libras de açucar tomareis e la mezclar e colarlo han, y de que este byen a punto an de tener cocidos los benbrillos en quartos y echarlos an en el açucar y yrlos deshaciendo con el cucharon y an de tener por su parte sacados tres quartilios de çumo de los benbrillos y yr de lo echando poco a poco hasta que este hecha la carne".

Además de las referencias a Castilla y Portugal, existían algunas otras a otros territorios de la Corona de Aragón, como la recetas de hojaldradas, lo que da idea de la síntesis que estaba ya entonces produciéndose entre las diversas culturas alimentarias de toda la península ibérica:

\section{"Para hazer ojaldras a la aragonesa y catalana}

Tomar la masa quando esta para poner al horno y conforme a la cantidad que quisieren hazer han de tomar dos partes de manteca de puerco y una de vaca que sea fresca y la han de revolver toda junta muy bien mezclada y menearanla con la masa estirandola de manera que haga correa y que sea muy bien sobada con la manteca despues echaran açucar molido muy bien y bueno que sea fino y mezclale an con la dicha masa, y si fueren tres libras de manteca echaran libra y media de açucar, y despues haran sus ojaldres encima de una oblea o un papel untado con manteca, y si quisieren poner encima unos torreznos sera muy bueno, despues echar agua rosada y açucar llevarlo a cozer al horno".

De gran importancia y significación es el Livro de cocinha da Infanta D. Maria de Portugal, un recetario de cocina portugués del siglo XVI que respondía a una clara tradición hispánica, por la estrecha relación existente entre la corte española y la corte portuguesa en esa época. Fue propiedad de Doña María de Portugal (Lisboa, 1538 - Parma, 1577), nieta del rey Manuel el Afortunado. Doña María se llevó el libro a Italia al contraer matrimonio con Alejandro Farnesio, duque de Parma. La boda se celebró en Bruselas el 30 de noviembre de 1565 .

Está escrito en lengua portuguesa y tenía como título "Trattato di cucina”, título al que se añadió posteriormente la palabra "spagnuolo". Participa de las características de los recetarios femeninos, por pertenecer a la Infanta Doña María de Portugal, pero se halla más próximo a los libros de cocina cortesana. 
Este manuscrito portugués, llevado a Parma por la princesa María en el siglo XVI, pasó posteriormente, en el siglo XVIII, de Parma a Nápoles, cuando el Infante don Carlos de Borbón, llevó consigo la herencia de los Farnesio a su reino de las Dos Sicilias, motivo por el cual el manuscrito se halla en la Biblioteca Nacional de Nápoles. ${ }^{10}$ En las últimas décadas ha sido varias veces editado. ${ }^{11}$

E1 texto recoge 61 recetas culinarias, divididas en cuatro partes. La primera, titulada "Caderno dos magares de carne", contiene 26 recetas a base de carne, lo que refleja claramente la importancia central de la carne en la alimentación de las clases privilegiadas. La segunda se titula "Caderno dos mangares de ovos", que consta sólo de 4 recetas. La tercera lleva por título "Caderno dos mangares de leyte", con 7 recetas. Y finalmente la cuarta parte, con el título de "Caderno das cousas de comservas", con 24 recetas, que responde al interés que los recetarios femeninos suelen siempre poner en la conservación de los alimentos y en las diversas maneras de conservarlos, tanto por razones de economía, como por razones de gusto. ${ }^{12}$

También en este recetario existen varias referencias a recetas de otras damas, como las "tigeladas de leite de Dona Isabel de Villena" y las "almojávenas de Dona Isabel de Villena”.

Incluye muchas recetas de tradición hispánica. Algunas de la cocina castellana, otras relacionadas con la cocina catalana, como el famoso manjar blanco. La receta se halla en muchos recetarios de la época. Para algunos las primeras recetas aparecieron en libros franceses, como el Viandier de Taillevent y en el Ménagier de Paris, ambos del siglo XIV. ${ }^{13}$ Otros lo vinculan con la cocina germánica. ${ }^{14}$ Pero también existen indicios que lo relacionan con la cocina catalana. Arnau de Vilanova, recomendaba en su Regimen sanitatis ad regem Aragonum, escrito en 1308, el manjar blanco con capón o pechuga de pollo para convalecientes y personas delicadas. Encontramos recetas de manjar blanco en el manuscrito del Sent Soví de 1324 y en el Libre del coch del Mestre Robert de 1520. Es significativo que aparezca en versión catalana en algunos recetarios italianos, así el Libro de Arte Coquinaria, del Maestro Martino da Como, que incluye una receta de "Bianco mangiare al modo catalano", y el humanista Bartolomeo Sacchi, de nombre latino Platina, en su obra De honesta voluptate et valetudine, publicado por primera vez en latín, en Roma, seguramente en 1474, que incluye dos versiones de "Biancomangiare alla catalana"

\footnotetext{
${ }^{10}$ B N N. Mss. I. E. 33.

${ }^{11}$ Newman 1964. Manuppella, Dias Arnaut 1967. Manuppella 1986. Palla, M.J. 2008.

${ }^{12}$ Buescu 2010. Oliveira Marques 2010. Braga 2007.

${ }^{13}$ Colson 2012.

${ }^{14}$ Ehlert 2002.
} 
La receta que ofrece el libro de la infanta María es la siguiente:

\begin{abstract}
"Manjar branco
Tomareis o peito de uma galinha preta e pô-lo-eis a cozer sem sal, senão na água, e há-de ser não muito cozida, para que se possam tirar as fêveras inteiras. (...) E para este peito é mister um arretel de arroz (...) e uma camada de leite deitada no tacho, e sete onças de açúcar. E tomareis a galinha e darlhe-eis três machucadas num gral, e deitá-la-eis a farinha de arroz e (...) o sal com que se tempere, muito bem mexido. Então, pô-lo-eis no fogo e (...) a tempo batereis. Quando estiver cozido, deitar-lhe-eis o açúcar e, se não for muito doce, poder-lhe-eis lançar mais; e, como for cozido, tirai o tacho fora e enchei as escudelas e deitai-lhe açúcar pisado por cima”.
\end{abstract}

Otras son recetas típicas de la cocina castellana, con pretendida influencia de la tradición musulmana, como la gallina morisca, con la paradoja de elaborar la receta con manteca de cerdo.

\title{
"Galinha Mourisca
}

Tomareis uma galinha crua e fá-la-eis em pedaços. Então metê-la-eis numa panela e tomareis uma cebola e salsa, coentro e hortelã, tudo verde, e segá-lo-eis como para salada, e com duas colheres de manteiga e uma talhada de toucinho tamanho como meio ovo, e isto tudo dentro da panela com a galinha e com tudo bem afogada. E dês que for afogada, deitar-lhe-ão água, quanta bastar para se cozer a galinha, porque lhe não hão-de tornar a deitar mais água. E dês que for acerca cozida, deitar-lhe-ão os adubos e deitar-lhe-ão sumo de limões. E depois que for muito bem cozida tomareis um pão e fatiá-lo-eis num prato, e deitareis a galinha em cima, e por cima da galinha poreis umas gemas escalfados, e por cima canela pisada."

Entre los platos de huevos, no podían faltar diversas recetas de "huevos mexidos”, que tendrán gran influencia en la cocina española.

\section{"Canudos de ovos mexidos}

Misturem as gemas de ovos e deitem-nas a cozer em calda rala, sem mexer, para que não se quebrem. Façam uma massa, bem sov da, de farinha de trigo, manteiga, água-de-flor e uma pitada de açafrão. Em seguida, abram-no com um rolo, como para pastel, façam os canudos e fritem-nos. Recheiem então os canudos com o doce de ovos já pronto, e passem-nos pela calda de açúcar. Polvilhem com açúcar e canela.”

De una dama noble es también otro manuscrito algo posterior. Titulado "Recetas y memorias para guisados, confituras, olores, aguas, afeites, adobos de guantes, ungüentos y medicinas para muchas enfermedades”, 
es un manuscrito del siglo XVI, con muchas adiciones posteriores del siglo XVII. ${ }^{15}$

En total consta de 207 recetas, la mayoría de cocina, 150, y el resto repartidas entre belleza y salud. Las recetas de cocina son muy variadas, potajes, platos de carne y volatería, pasteles salados y dulces, salsas y confituras. No faltan recetas de origen portugués: "Para azer texeladas portuguesas". La mayoría son dulces tradicionales como la llamada Torta Real.

\section{"Torta Real}

Tomareis media libra de almendras peladas y porneislas en una escudilla con leche de manera que esten cubiertas y esten desta manera veinte y quatro horas y despues que ayan estado dicho tienpo sacatlas y picaldas que esten bien picadas $\mathrm{y}$ tomareis das ancilletol de un dinero de requeson que sea bien prieto y una libra de açucar del fino y picareis primero el requeson y despues almendras picadas y todo junto bolverlo eis a picar y de otra parte picareis el açucar que este como arma y despues mesclarlo eis con las almendras y el requesan de manera que este bien mezclado en el mortero y despues porneis media escudilla de leche de cabras $\mathrm{y}$ tomareis tres blancos de huevos y seis yemas y mezclarlo eis todo en el mortero $\mathrm{y}$ tomareis arma de candeal para azer el delgado y poneis a un blanco de huevo das yemas que sea bien dura la masa y azeis un delgado con un canyon de caña y porneislo en una tortera de aranbre que tenga quatro dedos de cantos y porque no se apegue untaría eis con azeite y poneis la tortera sobre un foguer porque se cuaje el delgado ante de poner lo que estara en el mortero y despues porneis lo que estara en el mortero y inviarla eis al orno y cueza sin lunbre quando el horno este cansado y quando estara cozida sacatla del orno ponle mucho açucar porque aga costra y el sacar de la tortera agase de manera que no se apegue ni se ranpa y quando stara fria porneis açucar encima".

La fama de los dulces portugueses fue siempre muy reconocida en España. Sirva de indicio una carta de Felipe II a sus hijas, fechada en Lisboa, el 15 de enero de 1582 en que el rey anuncia a las infantas el envío de un dulce: "Diéronme el otro día lo que va en esa caja y dixéronme que era lima dulce, y aunque no creo que es sino limón os lo he querido enviar, porque si fuere lima dulce no he visto ninguna tan grande..."16

\footnotetext{
${ }^{15}$ BNE, Mss/6058.

${ }^{16}$ Fabié 1884: 255.
} 


\section{Recetas portuguesas en los libros de cocina españoles Del SIGLO XVII}

Relación con Portugal tuvo el más famoso cocinero español de la Corte de los Austrias, Francisco Martínez Montiño, cocinero de los reyes Felipe III y Felipe IV, autor del famoso libro Arte de cocina, pasteleria, vizcocheria y conserveria, publicado en Madrid, por Luis Sánchez, en 1611. ${ }^{17}$

Según confiesa en el prólogo de su obra, desde niño había aprendido el oficio en la cocina de la infanta Doña Juana, madre del rey don Sebastián de Portugal, cocina que pone como ejemplo de buena organización, citando como testigos de su afirmación al cocinero mayor de la Reina, - entonces Margarita de Austria, esposa de Felipe III -, Juan de Mesones, y su ayuda, Amador de Aya. De estos orígenes podría acaso proceder la influencia lusitana que se detecta en el recetario y que refleja la larga tradición de relaciones entre las cocinas cortesanas española y portuguesa.

Francisco Martínez Montiño fue cocinero del futuro Felipe III desde que se le puso Casa siendo príncipe heredero, en 1585, y siguió a su servicio al convertirse en rey en 1621 y durante todo su reinado. Le sirvió en el Alcázar de Madrid y en los Reales Sitios próximos, y le siguió en todas las jornadas, durante los años de estancia de la Corte en Valladolid y también durante el viaje a Portugal.

Fue primero ayuda de cocina, alcanzando después el puesto de cocinero mayor, cargo que ocupaba en 1611 fecha de la publicación de su recetario. En septiembre de 1620 presentó un memorial en el que afirmaba llevar treinta y cuatro años sirviendo el oficio, después haber servido otros cinco años a Doña Juana. Declaraba como mérito haber acompañado al rey en todas sus jornadas y no haber recibido nunca ninguna retribución extraordinaria. ${ }^{18}$ Francisco Martínez Montiño continuó como cocinero mayor de Felipe III hasta la muerte del monarca en 1621. Después siguió unos años como Cocinero de la Servilleta del nuevo rey Felipe IV. Su presencia en las cocinas de palacio está constada al menos hasta 1629, en que se retiró o murió.

El libro de Martínez Montiño responde al modelo de cocina cortesana del barroco y refleja la compleja síntesis alimentaria que se había forjado en la Monarquía Española como resultado de la incorporación de las variadas tradiciones culinarias de los diversos territorios que la formaban, sobre todo europeos, pero también americanos y asiáticos. La posible influencia portuguesa vendría dada por la larga vinculación de las cocinas cortesanas de España y Portugal, por la formación de Martínez Montiño en la cocina de Doña Juana e incluso por el viaje a Portugal en el séquito real en 1619.

\footnotetext{
${ }^{17}$ Martínez Montiño 1611.

${ }^{18}$ AGP: Histórica, Caja 634, no 56. Personal, Caja 626/30 y 1015/4. Administración leg. 1135.
} 
En el Arte de cocina, pasteleria, vizcocheria y conserveria hay varios platos “a la portuguesa”, una receta de ave, una de arroz, una de espinacas, y dos de sopas.

\section{"Una ave a la portuguesa}

Tomarás una ave cocida y rellena, salpimentada, y asentarla has sobre ojuelas, y acercarla has con huevos hilados, y conservas, como son cermeñas, y diacitrón cortado, y otras conservas, y ojuelas: este plato se sirve frío."

\section{"Arroz a la portuguesa}

Harás una libra de arroz con leche, de la manera que està dicho arriba, y quando lo quisieres servir, batirás una docena de yemas de huevos muy batidas, y pondrás el arros sobre la lumbre, è irás echando estas yemas de huevos, y revolviendo muy apriesa; y dando un hervor, sacalo, y echalo en los platos, y pon el azúcar, y canela por encima, y sírvelo caliente."

\section{"Espinacas a la portuguesa}

Echarás el aceyte en una cazuela, y quando esté caliente, tendràs las espinacas mojadas, y lavadas, y quitados todos los pezones, y muy esprimidas del agua, y las irás echando en el aceyte meneándolas con un cucharon, y ellas se irán allí ahogando, de manera que vendrán á caber muchas en la cazuela, y ellas mismas harán un caldillo, y echarás allí mucho cilantro verde; y después que estén bien ahogadas sazonalas de especias, y sal, y echales un poco de mas agua caliente que se bañen bien, y echales vinagre, que estén bien agrias: luego echales allí quatro, ó seis huevos crudos, que se escalfen en las mismas espinacas, y cubre la cazuela para que los huevos se pongan duros, y sírvelos en la misma cazuela."

\section{"Sopas a la Portuguesa}

Echaràs à cocer vaca, que sea manida y gorda, $\mathrm{y}$ le pondrás un ave, y pedazo de tocino de pernil, y algun brazuelo de carne; y quando estè cosida la vaca, ponle de todas verduras, y una rama de eneldo, y un cogollo de poleo, y poco de jadrea, y mucha cantidad de cilantro verde, no ha de llevar ninguna especia. Le has de poner tanto vinagre como quepa en una cascara de avellana, pruébala de sal; luego haràs la sopa en una porcelana grande, ò almofía. El pan ha de ser mollete; y no se ha de cortar con cuchillo, sino con la mano, unos pedacitos grandes como nueces, y mayores, y los mojaràs con el caldo de la vaca, de manera que no estèn muy empapadas las sopas; y servirás encima unas revanadas de vaca gorda. Algunos señores no quieren eneldo, porque tiene mucho humo; y en su lugar podrás poner unos cogollitos de verzas."

\section{"Sopa de vaca á la Portuguesa, contrahecha en dia de pescado}

La sopa de vaca se contrahace en dia de pescado, de esta manera. Tomarás verzas crudas, que sean repolludas, y hinche una olla dellas, y ponle dentro cantidad de cilantro verde, y unas matas de yerbabuena, y un manojillo de ajedrea, y tres, ò quatro cogollos de sándalos; y ponle un poco de buena manteca de vacas; luego 
echale el agua que pudiera entrar hasta que se hincha; sazonala de sal, y ponla à cocer, hasta que estén las verzas cocidas, y tendrás las sopas, el gusto, como las de vaca. Estas sopas à la Portuguesa, comen mucho los Portugueses.”

Otros platos, aunque no llevara la receta en el título la referencia "a la portuguesa", tenían clara ascendencia lusa, como era el caso de los "huevos mexidos", como indica su mismo nombre.

\section{"Huevos mexidos}

Para hacer un plato de huevos mexidos, harás almivar de una libra de azúcar, y batirás veinte y quatro yemas de huevos, y pondrás el azúcar donde cueza muy apriesa; luego echarás todos los huevos juntos sobre el almivar; de manera que suba el almivar por encima de todos los huevos, y asi irás haciendo el bollito de los huevos mexidos; y si los quieres servir juntos con el mismo cacito, lo podrás echar sobre el plato, poniendo debaxo unas ojuelas, ò unas revanaditas de pan, y si no sírvelo en pepitas, adornando el plato con algunas conservas."

Varios fueron los cocineros que en 1619 viajaron a Portugal con Felipe III y que pudieron así tener ocasión de conocer directamente la cocina portuguesa. Entre los cocineros de la corte de Felipe IV destaca, además de Martínez Montiño, Toribio de Agüero. Siendo cocinero mayor del rey Felipe IV escribió en 1622 un memorial en el que afirmaba: "A 34 años que sirve al agüelo [Felipe II] y madre [Margarita de Austria] de V.M. que santa gloria ayan y a V.M. desde que nació, yendo a todas las jornadas que se han ofrecido en este tiempo (...) y en la xornada de Portugal le robaron quanto tenía en tanto que estaba en servicio de V.M.” Toribio de Agüero murió en 1635.

Otro recetario de la época es el de Domingo Hernández de Maceras, titulado Libro del arte de cocina, publicado en Salamanca, el año 1607. Obra del cocinero del Colegio Mayor de Oviedo de la Universidad de Salamanca, refleja la alimentación de una comunidad de estudiantes privilegiados, una buena alimentación, pero sin las fantasías de la cocina cortesana. ${ }^{19}$

Hernández de Maceras da una receta de cazuela de conejos a la portuguesa.

\section{"Como se ha de hazer una caçuela de conejos a la Portuguesa}

"Despues de medio assados los conejos, hanse de hazer pedaços del lomo dos, y las piernas cada una de por si, y el cuerpo otros dos pedaços: y la cabeça de por si: y se han luego de echar en una olla o caçuela, y después se ha de freyr un poco de cebolla picada muy menuda, y echarla en los conejos, y para cada conejo es

\footnotetext{
${ }^{19}$ Pérez Samper 1998.
} 
menester dos maravedís de especias, y quatro de azeyte: y se le echara todo este recaudo con sal, y vinagre, y agua, poniéndolos a cozer, y no cozerá mas de media hora, porque se desmenuza mucho. Llamase este plato a la Portuguesa, y es el mejor de todos los conejos. También se pueden dar assados enteros, con azeyte, vinagre, y pimienta: y estos se darán mechados.”

También incluye Hernández de Maceras en su libro una receta de "huevos mexidos", que llama "mecidos":

\section{"De huevos mecidos}

Para hazer dos dozenas de huevos, toma tres quarterones de açucar piedra y echa media libra en un caço con un quartillo de agua, y medio quartillo de vino blanco y una poca de agua de azahar, y se mezclará todo en el caço con el açucar y se pondrá a la lumbre, y se hará un almíbar y, estando hecho, estaran los huevos batidos, y no se les echaran las claras sino las yemas, y no se han de batir con hierro, sino con un cucharón, y se echaran en el almibar, poniéndolos con poca lumbre para que se vayan coajando poco a poco y, de quando en quando, menealos con un cucharon, y en estando secos, apartalos de la lumbre, y de las claras se haran torrijas, poniéndolas en los platos, y echando los huevos por encima: y moliendo el otro quarterón de azúcar con canela, y echandoselo por encima a los huevos: y de estos huevos mecidos se pueden dar unos pastelillos de massa fina rellenos con unas tajadas de diacitrón, o unas guirnaldillas de massa fina para differenciar platos en comidas de viernes, o de sabados."

Las referencias a la cocina portuguesa en el título de las recetas son múltiples. En el libro de Miguel Yelgo de Bázquez, titulado Estilo de servir a príncipes, publicado en Madrid, por Cosme Delgado, en 1614, aunque no era propiamente un libro de cocina también había referencias "a la portuguesa". Entre los platos que Yelgo de Báquez consideraba que debía conocer un cocinero para servir a una mesa señorial, citaba dos "a la portuguesa": "Bollos de Ribilla a la Portuguesa" y "Conejos a la Portuguesa”. ${ }^{20}$

También se servían en el siglo XVII diversos platos "a la portuguesa" en la mesa de los Duques de Gandía, como "carnero a la portuguesa, con especias" y "gigote a la portuguesa, con especias". ${ }^{21}$

\section{LA COCINA PORTUGUESA DEL SIGLO XVII ¿COINCIDENCIAS IBÉRICAS?}

E1 referente por excelencia para la cocina portuguesa de la edad moderna es el libro de Domingos Rodrigues, titulado Arte de cozinha, publicado en 1680.

\footnotetext{
${ }^{20}$ Yelgo de Bázquez 1614. Pérez Samper 2000-2001: 315-359.

${ }^{21}$ ACN, Osuna, leg. 806-30. Pérez Samper 2004.
} 
Domingos Rodrigues es el cocinero portugués más famoso de la época moderna. Nacido en Vila Cova à Coelheira, obispado de Lamego, en 1637, murió en Lisboa, en 1719. Trabajó como cocinero para diversas casas nobles, como la del conde de Vimioso y marqués de Valença, Gobernador Militar de Évora durante la "Guerra da Restauração". Las primeras ediciones del libro de cocina están precisamente dedicadas a su señor, el Conde de Vimioso. Según se dice en posteriores ediciones fue también maestro de cocina de la corte, seguramente en tiempos de Pedro II, primero Regente y después Rey de Portugal (1683-1706), y de Juan V (1706-1750).22

Importante pudo ser también para la cocina de Domingos Rodrigues la figura de la reina Maria Francisca de Saboya (1646-1683), hija del Duque de Nemours, casada primero com Alfonso VI y después con Pedro II en 1668. El prestigio de la cocina francesa, entonces el modelo gastronómico por excelencia, y las costumbres culinarias que la reina trajo consigo a Portugal influyeron en la obra de Rodrigues. Un nuevo indicio de la importante influencia que las reinas tuvieron en la difusión de los modelos de cocina cortesana.

El éxito fue duradero. El libro tuvo numerosas ediciones, tres en el siglo XVII, en 1680, 1683 y 1698. En el siglo XVIII se hicieron varias ediciones, en 1732, 1741, 1758, 1765 y 1794. Siguió editándose en el siglo XIX.

Primero constaba de dos partes, así por ejemplo la edición de 1683: Arte de cozinha dividida em duas partes, a primeyra trata do modo de cozinhar varios pratos de toda a casta de carne, E' de fazer conservas, pasteis, tortas, E empadas. A segunda trata de peyxes, marisco, fruttas, hervas, ovos, lacticinios, conservas, E' doces: com a forma dos banquetes para qualquer tempo do anno. / Composta, E̋ de novo accrescentada por Domingos Rodriguez...

Después el libro se amplió y pasó a tener tres partes, como en la edición publicada en Lisboa en 1732: Arte de cozinha, dividida em tres partes. A primeira trata do modo de cozinhar varios pratos de todo o genero de carnes, $e$ de fazer conservas, pasteis, tortas, e empadas. A segunda trata de peixes, marisco, frutas, hervas, ovos, lacticinios, doces, e conservas, pertencentes ao mesmo genero. A terceira trata da fórma de banquete para qualquer tempo do anno, e do modo com $q$ se hospedaraó os embaixadores, e como se guarnece huma mesa redonda à estrangeira. Composta e terceira vez accrescentada por Domingos Rodrigues, Mestre da Cozinha de Sua Magestade.

Finalmente pasó a tener cuatro partes, así sucedió en la edición de 1821: Arte de cozinha dividida em quatro partes, a primeira trata do modo de cozinhar varios guizados de todo o genero de carnes, e conservas, tortas, empadas, e pasteis. A segunda de peixes, mariscos, frutas, hervaa [sic], ovos, lacticinios, doces, conservas do mesmo genero. A terceira de preparar mezai [sic] em todo o tempo do anno, para

${ }^{22}$ Buescu y Felismino 2011. 
hospedar principes, e embaixadores. A quarta de fazer pudins, e preparar massas... Correcta, e emendada nesta ultima edição. / Author Domingos Rodrigues...

E1 libro de Domingos Rodrigues es la representación de la cocina cortesana barroca portuguesa, con significativas influencias extranjeras, especialmente de Francia, que estaba creando en esas mismas fechas el modelo por excelencia de la alta cocina, destinado a difundirse por toda Europa y a triunfar por largo tiempo. Reflejo del cosmopolitismo característico de la cocina cortesana, hay recetas "a la francesa", "a la italiana", "a la inglesa". ${ }^{23}$

Tiene muchas coincidencias con los recetarios españoles del siglo XVII, especialmente con el libro de Francisco Martínez Montiño, indicio claro de la base común de la cocina ibérica. Pero más allá de las indudables similitudes, existe un notorio distanciamiento. Como consecuencia de la separación de los reinos, no hay recetas tituladas "a la española", pero algunas son muy similares a las españolas.

Muy significativa es la receta del plato estrella de la cocina hispánica desde finales de la edad media, el "Manjar blanco":

\section{"Manjar branco}

Depois que hum peito de galinha estiver meyo cozido, desfiado, e desfeito em hum tacho com a colher deitem-lhe duas canadas de leite, dous arrateis de açucar, e arratel e quarta de farinha de arroz, e mexendo-se tudo muito bem, ponha-se a cozer: em quanto se vay cozendo deitem-lhe pouco a pouco meya canada de leite, para se refrescar, e hum arratel de açucar: como estiver cozido (que se pode conhecer, se metendo-lhe a ponta de huma faca, despegar lizo) deitem-lhe agua de flor, tire-se do lume, e corte-se em pélas.

Do mesmo modo se faz de peixe, ou de lagosta em lugar de gallinha."

Igualmente característica era la "gallina morisca":

\section{"Galhina mourisca}

Ponha-se a frigir hum arratel de toucinho, cortado do tamaño de dados, e deite-se o pingo limpo dos torresmos en huma tigela com o pingo de huma gallinha, que ha de estar meya assada, hum golpe de vinho branco, pouco vinagre, agoa a que baste, e ponha-se a afogar, tempere-se com todos os adubos com duas folhas de louro, e coalhese com duas gemas de ovos: poem-se satias por baixo, e limão por sima.

Deste modo se fazem perú, pombos, cabrito, e lombos.”

Todavía más significativa era la presencia del plato típico por excelencia de la cocina española de la edad moderna, la famosa "olla podrida":

\footnotetext{
${ }^{23}$ Braga 2006, II, 237-247. Pereira, 2000, 2009 e 2011.
} 


\section{"Olha podrida}

Ponha-se em huma panela a cozer hu pedaço de vacca muito gordo, huma gallinha, huma adem, huma perdiz, ou pombos, hum coelho, huma lebre, havendo-a huma orelheira, ou pá, se for tempo de porco, hum pedaço de lacão, chouriços, lingoiça, e lombo de porco, tudo misturado com nabos, se os houver, ou rabãos, tres cabeças de alhos grandes, duas, ou tres duzias de castanhas, sal, e cheiros: como estiver cozido, mandese à mesa em hum prato sobre sopas de pão.”

Célebre por la variedad y refinamiento de sus platos y menús, el recetario tuvo gran divulgación en su época, se hicieron diecinueve ediciones. Es considerado el libro de cocina más antiguo de la culinaria lusa. ${ }^{24}$

La tendencia de la cocina portuguesa a distanciarse de la española se mantuvo en el siglo XVIII. Aunque en el fondo existían muchas relaciones y coincidencias, en los recetarios no se hacían demasiado visibles. En el libro de Lucas Rigaud, Cozinheiro Moderno ou Nova Arte de Cozinha, cuya primera edición es de 1780, las recetas se atribuyen con frecuencia a diversas procedencias, portuguesas, francesas, italianas, inglesas, alemanas, pero son muy raras las recetas atribuidas a un origen español. Existe una de "Massa a Hespanhola" y otra de "Molho a la Hespanhola". ${ }^{25}$ Pese a todo el modelo de cocina ibérica siguió existiendo, como se puede apreciar en el contenido de las recetas, aunque no se refleje en sus títulos.

\section{INFLUENCIAS PORTUGUESAS EN LA CONFITERÍA ESPAÑOLA DEL SIGLO XVIII}

El libro de confitería más representativo de la España del Siglo XVIII fue obra de Juan de la Mata: Arte de reposteria, en que se contiene todo genero de hacer dulces secos, y en liquido. Se publicó en Madrid, en 1747, con la Aprobación de Domingo Fernández, repostero del rey. ${ }^{26} \mathrm{~A}$ la tradición española, Mata sumó las novedades de moda en Francia, incorporando la confitería al afrancesamiento general que experimentaba la alta cocina española de esa época. El autor reconoce haber tenido maestros franceses, italianos y de otras naciones. ${ }^{27}$

Pero a pesar de ese afrancesamiento, la sólida base ibérica persistía. Son muchas las recetas que en el libro de Juan de la Mata llevan en el título la referencia a Portugal por diferentes motivos.

Las más numerosas son las que se refieren a las naranjas de Portugal en diversas preparaciones: "Naranjas de Portugal en quarterones ó rajitas", "Naranjas de Portugal enteras", "Naranjas de Portugal en aguardiente", "Mermeladas de naranjas de Portugal" y "Agua de naranjas de Portugal".

\footnotetext{
${ }^{24}$ Rodrigues 1987.

${ }^{25}$ Rigaud 1780.

${ }^{26}$ Mata 1747.

${ }^{27}$ Pérez Samper 2011.
} 
También hay recetas de compotas de diversas frutas "a la portuguesa": "Otra manera de compotas de albaricoques a la portuguesa" y "Compota de manzanas a la portuguesa”.

Finalmente había recetas de "Vizcochos de Portugal", que llevaban entre sus ingredientes mermelada de naranjas de Portugal.

Tampoco podía faltar una receta de huevos:

\section{"Huevos a la portuguesa}

Desleiráse en agua de azar azúcar, según la cantidad, y en dos zumos de limón: y todo incorporado se pondrá en el fuego, aumentado de dos hiemas de huevo, removiéndolo con una cuchara de plata: quando los huevos naturalmente se aparten del plato, estarán cocidos, restando solo dexarlos enfriar, y servirlos en forma de pyramide, guarnecidos de corteza de limón confitado y mazapán.

Sirvanse también calientes en su plato: y para esto se pasarà por encima, à fin de que reciban color, una pala de fuego bien encendida, bañándolos últimamente con azúcar."

Recogía también Juan de la Mata en su libro una receta de "Nata a la portuguesa", aromatizada con limón o naranja y con canela:

\section{"Nata a la portuguesa}

Con medio quartillo de buena nata se mezclarà un quartillo de leche dulce $\mathrm{y}$ fresca, tres hiemas de huevo, azúcar en polvo a discreción, un pedacito de canela, y otro tanto de corteza de limón ò naranja confitada, dividida en pequeños trozos, y todo se pondrá al fuego, dexandola hervir hasta que parezca que se quiere pegar al perol o cazo, moviéndolo (como dicho es) con el cucharon continuamente, y puesta en una porcelana se podrá servir.”

Podrían ponerse muchos otros ejemplos. Merece la pena hacer una comparación cuidadosa de las mutuas influencias entre la cocina española y portuguesa. En mi opinión, existen muchas pruebas, las suficientes, para concluir la existencia de una cocina común ibérica, con una fuerte identidad diferencial frente a otras cocinas europeas, y por supuesto, todavía más, americanas y asiáticas, hasta donde llegó la influencia ibérica. Una cocina ibérica común, aunque con diversas características regionales, igualmente bien definidas, como señalan las coincidencias y diferencias entre la cocina portuguesa y la cocina española, entre la cocina atlántica y la cocina mediterránea, entre la cocina cortesana y la cocina popular.

\section{Bibliografía}

Algranti, L.M. (2010) "Notas sobre a mesa da casa real portuguesa no reinado de D. José I", in I. dos Guimaraes Sá, M. García Fernández (coords.) Portas adentro: comer, vestir e habitar na Peninsula Ibérica (ss. XVI - XIX),. Universidad de 
Valladolid, Secretariado de Publicaciones e Intercambio Científico, Universidade de Coimbra, Coimbra, 87-116.

Borges, I. C. C. 2011 "A Fruta na Gastronomia Quatrocentista/ Quinhentista e Seiscentista Portuguesa”, Estudio Avanzados 16: 71-102.

Braga, I. D. (2006), "Influências estrangeiras nos livros de cozinha portugueses (séculos XVI-XIX): alguns problemas de análise" in Estudos em homenagem ao Professor Doutor José Marques. Departamento de Ciências e Técnicas do Patrimónia, Departamento de História. Faculdade de Letras da Universidade do Porto, Porto, II, 237-247.

Braga, I. D. (2007), “À Mesa com Grão Vasco. Para o Estudo da Alimentação no século XVI”, Máthesis 16: 9-59.

Bruegel, M. y Laurioux, B. (eds.) (2002), Histoire et Identités Alimentaires en Europe, Hachette, París.

Buescu, A.I. (2010) "À mesa do rei. Cultura alimentar e consumo no século XVI", in I. dos Guimaraes Sá, M. García Fernández (coords.) Portas adentro: comer, vestir e habitar na Península Ibérica (ss. XVI - XIX),. Universidad de Valladolid, Secretariado de Publicaciones e Intercambio Científico, Universidade de Coimbra, Coimbra, 19-46.

Buescu, A.I. y Felismino, D., (coord.) (2011) A Mesa dos Reis de Portugal. Ofícios, Consumos, Cerimónias e Representações (Séculos XIII-XVIII), Temas e Debates / Círculo de Leitores, Lisboa.

Chaunu, H y P. (1955-1960), Séville et l'Atlantique (1504-1650),SEVPEN, París.

Colson, M. (2012), "La recette du blanc-manger: de la variation à la degustation”, in P. Renders, y M. Steffens, 4e Journée liégeoise de Traitement des Sources galloromanes (TraSoGal), Liège. http://hdl.handle.net/2268/171186.

Dias Arnaut, S. (1986), A Arte de Comer em Portugal na Idade Média, Imprensa Nacional Casa da Moeda, Lisboa.

Ehlert, T. (2002), "Les Manuscrits Culinaires Médievaux témoignent d'un Modèle Alimentaire Alemand", in M. Bruegel e B. Laurioux (dirs.), Histoire et Identités Alimentaires en Europe, Hachette, Paris, 121-136.

Fabié, A. M. (1884), "Cartas de Felipe II á las infantas sus hijas”, in Boletín de la Real Academia de la Historia, Madrid.

Flandrin, J.-L. (1984), "Internationalisme, Nationalisme et Régionalisme dans les Cuisines des XIV et XV siècles", Manger et Boire au Moyen Âge, tomo 2, Centre d'Études Médiévales de Nice, Niza, 75-91.

Gonçalves, I. (1988), “Acerca da Alimentação Medieval”, Imagens do Mundo Medieval, Lisboa, Horizonte, 201-217.

Gonçalves, I. (1992-1993), “A Colheita Régia Medieval, Padrão Alimentar de Qualidade (Um Contributo Beirão)”, Revista da Faculdade de Ciências Sociais e Humanas, 6: 175-189.

Gonçalves, I. (1997), “À Mesa, com o Rei de Portugal (séculos XII-XIII)”, Revista da Faculdade de Letras, 2.14: 13-32. 
Guevara, A. (1850), Epistolas Familiares, Rivadeneyra, Biblioteca de Autores Españoles, Madrid.

Hordenanzas y etiquetas que el rey nuestro señor don Pelipe segundo rey de las Españas mando que guardasen por los criados y criadas de la real cassa de la reyna nuestra señora, dadas en treinta y uno de diziembre de mil quinientos y setenta y cinco años. y refrendadas por su secretario de estado Martín de Gaztelu. Archivo General de Palacio [AGP], Sección Histórica, caja 49, exp. 3.

Livro de receptas de pivetes, pastilhas e vvas perfumadas y conserbas. B.N.E. Biblioteca Nacional de España, Madrid, Mss. 1462.

López Piñero, J.M. (1991), El vanquete de nobles cavalleros (1530) de Luis Lobera de Ávila y la higiene individual del siglo XVI, Ministerio de Sanidad y Consumo, Madrid.

Madrid, AGP. Archivo General de Palacio, Histórica, Caja 634, no 56. Personal, Caja 626/30 y 1015/4. Administración leg. 1135.

Manuppella, G. y Dias Arnaut, S. (1967) O "livro de cozinha" da infanta D. Maria de Portugal, Acta Universitatis Conimbrigensis, CXLV. Coimbra.

Manuppella, G. (1986) Livro de cozinha da Infanta D. Maria: códice português I. E. 33 da Biblioteca Nacional de Nápoles, Imprensa Nacional - Casa da Moeda, Lisboa.

Martínez Montiño, F. Cocinero Mayor del Rey Nuestro Señor (1611), Arte de cocina, pasteleria, vizcocheria y conserveria, Luis Sánchez, Madrid. BNE, R/1472. Ed. facsímil (1982) Tusquets Editores, Barcelona.

Mata, J. (1747), Arte de reposteria, en que se contiene todo genero de hacer dulces secos, y en liquido. Antonio Marín, en casa de Simón Moreno, Madrid. BNE, R/40066.

Newman, E. (1964), A Critical Edition of an Early Portuguiese Cook Book, University of North Carolina, Chapel Hill.

Oliveira Marques, A.H. (2010), A Sociedade Medieval Portuguesa. Aspectos da vida quotidiana, A Esfera dos Livros, Lisboa.

“O Livro de Cozinha da Infanta D. Maria de Portugal”. B.N.N. Biblioteca Nacional de Nápoles "Vittorio Emanuelle III". Códice Portugués I. E. 33.

Palla, M. J. (2004) «Comida em Portugal no limiar do Mundo Novo», in A. J. Vilarinho, (coord.), A Volta da Mesa, IEFP, Lisboa, 33-37.

Palla, M. J. (2008) Livre de Cuisine de l'Infante Maria du Portugal, Tradução. Instituto de Estudos Medievais, Faculdade de Ciências Sociais e Humanas, Universidade Nova de Lisboa. Lisboa.

Pereira, A. M. (2000) Mesa Real. A dinastia de Bragança, Edições INAPA, Lisboa.

Pereira, A. M. (2009) "A mesa na Casa de Bragança», in Bragança Marca a História, a História Marca Bragança, Câmara de Bragança, Bragança.

Pereira, A. M. (2011) “Ofícios de Boca na casa Real Portuguesa (séculos XVII e XVIII)”, in A mesa dos Reis de Portugal, Circulo de leitores, Lisboa.

Pérez Samper, M. A. (1997), "Los recetarios de mujeres y para mujeres. Sobre la conservación y transmisión de los saberes domésticos en la época moderna”, Cuadernos de Historia Moderna 19: 121-154. 
Pérez Samper, M. A. (1998), La alimentación en la España del Siglo de Oro. Domingo Hernández de Maceras "Libro del Arte de Cocina", La Val de Onsera, Huesca.

Pérez Samper, M. A. (2000), "La alimentación en tiempos del Emperador: un modelo europeo de dimensión universal”, in J. L. Castellano Castellano y F. SánchezMontes González, (coord.), Congreso Internacional Carlos V, Europeísmo y Universalidad, Sociedad Estatal para la Conmemoración de los Centenarios de Felipe II y Carlos V y Universidad de Granada, Madrid, vol. V, 497-540.

Pérez Samper, M. A. (2000-2001), "Estilo de servir a príncipes. La cocina y la mesa de un Grande de España en el Siglo de Oro", Trocadero. Revista de Historia Moderna y Contemporánea 12-13: 315-359.

Pérez Samper, M. A. (2004), "La comida escrita en la España del Siglo de Oro", Food E History 2.1: 85-136.

Pérez Samper, M. A. (2011), Mesas y cocinas en la España del siglo XVIII, Trea, Gijón.

Recetas y memorias para guisados, confituras, olores, aguas, afeites, adobos de guantes, ungüentos y medicinas para muchas enfermedades, BNE, Biblioteca Nacional de España, Madrid, Mss. 6058.

Rodrigues, D. (1683) Arte de cozinha dividida em duas partes, a primeyra trata do modo de cozinhar varios pratos de toda a casta de carne, E de fazer conservas, pasteis, tortas, $\Xi^{\circ}$ empadas. A segunda trata de peyxes, marisco, fruttas, hervas, ovos, lacticinios, conservas, Eं doces: com a forma dos banquetes para qualquer tempo do anno. $\mathrm{Na}$ officina de Joaõ Galraõ : a custa de Manoel Lopes Ferreira, Lisboa.

Rodrigues, D. (1732), Arte de cozinha, dividida em tres partes. A primeira trata do modo de cozinhar varios pratos de todo o genero de carnes, e de fazer conservas, pasteis, tortas, e empadas. A segunda trata de peixes, marisco, frutas, hervas, ovos, lacticinios, doces, e conservas, pertencentes ao mesmo genero. A terceira trata da fórma de banquete para qualquer tempo do anno, e do modo com $q$ se hospedaraó os embaixadores, e como se guarnece huma mesa redonda à estrangeira. Officina Ferreiriana, Lisboa Occidental.

Rodrigues, D. (1821), Arte de cozinha dividida em quatro partes, a primeira trata do modo de cozinhar varios guizados de todo o genero de carnes, e conservas, tortas, empadas, e pasteis. A segunda de peixes, mariscos, frutas, hervaa [sic], ovos, lacticinios, doces, conservas do mesmo genero. A terceira de preparar mezai [sic] em todo o tempo do anno, para hospedar principes, e embaixadores. A quarta de fazer pudins, e preparar massas... na offic. da Viuva de Lino da Silva Godinho : vende-se na loja de João Nunes Esteves, Lisboa.

Rodrigues, D. (1987), Arte de Cozinha. Leitura, apresentação, notas e glossário por Maria da Graça Pericão e Maria Isabel Faria. Imprensa Nacional - Casa da Moeda, Biblioteca de Autores Portugueses, Lisboa.

Rodrigues, D. (2008), Arte de cozinha: As receitas da corte de Dom João. Introdução, Paula Pinto e Silva. Receitas de Flávia Quaresma e fotos de Sergio Pagano, Editora, Senac, Rio de Janeiro.

Rigaud, L. (1780) Cozinheiro moderno, ou nova arte de cozinha, onde se ensina pelo methodo mais facil..., Offic. Patriarc. de Francisco Luiz Ameno, Lisboa.

Rigaud, L. (1999) Cozinheiro Moderno ou Nova Arte de Cozinha, prefácio de Alfredo Saramago, Colares, Sintra. 
Historia de la alimentación: Relaciones entre España y Portugal en la edad moderna, a través de los recetarios

Santos, M. J. A. (1997) A alimentação em Portugal na Idade Média. Fontes. Cultura. Sociedade, Inatel, Coimbra.

Santos, M. J. A. (2002) Jantar e Cear na Corte de D. João III, Centro de História da Sociedade e da CulturaVila do Conde, Câmara Municipal de Vila do Conde, Vila do Conde.

Toledo, ACN. Archivo Central de la Nobleza, Osuna, leg. 806-30.

Yelgo de Bázquez, M. (1614), Estilo de servir a príncipes, Cosme Delgado, Madrid. BNE, $\mathrm{R} / 2868$. 